\title{
Administration of mucolytic solution before upper endoscopy - double-blind, monocentric, randomized study
}

\author{
Michal Stepan ${ }^{1,2}$, PremysI Falt' ${ }^{2}$, Barbora Pipek ${ }^{1,2,4}$, Petr Fojtik ${ }^{1,4}$, Martin Hanousek ${ }^{1}$, Martin Hill ${ }^{3}$, Ondrej Urban²
}

\begin{abstract}
Aims. Sufficient visibility of the mucosa during upper endoscopy is crucial for successful diagnosis, especially for early neoplastic lesions. Data documenting the effect of administration of mucolytic solution prior to gastroscopy in order to improve mucosal visibility are limited in Europe. The aim of the study was to assess the score of mucosal visibility in the upper gastrointestinal tract after administration of the mucolytic solution defined by us.

Patients and Methods. This is a monocentric, double-blind, randomized study involving 134 patients indicated for diagnostic upper endoscopy. Patients were randomly assigned to one of three arms, with mucolytic solution ( $100 \mathrm{~mL}$ water $+400 \mathrm{mg} \mathrm{N}$-acetylcysteine $+20 \mathrm{mg}$ simethicone), without the solution, and with $100 \mathrm{~mL}$ pure water. During the examination, 11 photographs were taken in defined areas. The visibility score was given by the sum of the score $0-5$ from 5 defined localities evaluated by a blinded endoscopist and subsequently by two blinded endoscopists. Other parameters monitored were examination time and a semiquantitative evaluation of residual gastric fluid.

Results. The basic characteristics of the group (sex, age, indications for examination) were comparable between arms. The visibility score was similar in all arms $-17.4 \pm 1.9$ vs. $17.0 \pm 2.0$ vs. $17.6 \pm 1.8(P=0.32)$. The examination time and the amount of residual fluid in the stomach were comparable in all arms.

Conclusions. Administration of the mucolytic solution in our study did not increase the mucosal visibility score in the esophagus, stomach and duodenum.

Trial Registration: ClinicalTrials.gov, NCT02967094.
\end{abstract}

Key words: upper endoscopy, visibility score, mucolytic solution, $\mathrm{N}$-acetylcysteine, simethicon

Received: March 7, 2021; Revised: June 7, 2021; Accepted: June 8, 2021; Available online: June 22, 2021

https://doi.org/10.5507/bp.2021.038

(c) 2023 The Authors; https://creativecommons.org/licenses/by/4.0/

'Digestive Diseases Center, Vítkovice Hospital, Ostrava, Czech Republic

${ }^{2}$ Department of Internal Medicine II - Gastroenterology and Hepatology, University Hospital Olomouc and Faculty of Medicine and Dentistry, Palacky University Olomouc, Czech Republic

${ }^{3}$ Institute of Endocrinology, Prague, Czech Republic

${ }^{4}$ Faculty of Medicine, University of Ostrava, Ostrava, Czech Republic

Corresponding author: Premysl Falt, e-mail: premysl.falt@fnol.cz

\section{INTRODUCTION}

Gastroscopy is the basic diagnostic method of the esophagus, stomach and duodenum. The number of performed gastroscopies has grown significantly in recent decades, as evidenced by data from the USA, where the number of endoscopies performed in the first decade of the new millenium increased by $50 \%$ and this trend continues ${ }^{1}$. As a result, there is a growing interest as well as need to determine the quality parameters of upper endoscopy. A number of European recommendations have been recently published, however, high quality indicators are still lacking, especially due to a lack of evidence in this area ${ }^{2,3}$. In its guidelines, European Society of Gastrointestinal endoscopy (ESGE) recommends fasting for 6 hours before the procedure as part of pre-procedural measures, while fluids can be ingested $2 \mathrm{~h}$ before the procedure ${ }^{3}$. However, as part of the diagnosis, especially for neoplastic lesions, a sufficiently clear mucosa in the upper digestive tract is necessary.

The visibility of the mucosa is most frequently reduced by the presence of mucus, bubbles, and food residues, bile and possibly blood ${ }^{4}$. Still discussed, but not used in routine practice in Europe, is the use of premedication using mucolytics (N-acetylcysteine, pronase) and simethicone with antifoam effect. Pronase is an enzyme with a proteolytic effect which is tested and used mainly in Asia, but it is not available in Europe. Simethicone is an antifoam agent that reduces the number of bubbles and is commonly used in Europe to improve the clarity of the mucosa during colonoscopy. A number of studies have been performed, especially in east Asia, which evaluated the visibility of the mucosa using these preparations in various combinations and doses with relatively good results ${ }^{4,5,7-9}$. Only a few studies have been performed in Europe; a Portuguese study showed a positive effect of self-administered simethicone and its combination with $\mathrm{N}$-acetylcystein ${ }^{10,11}$.

Unlike colonoscopy, no verified and generally valid scores are available to assess the quality of mucosal preparation in the upper gastrointestinal tract ${ }^{12}$. ESGE only recommends that information on gastric contents (bile, blood, dietary residues, presence of bubbles) be included in the gastroscopic examination report ${ }^{3}$. 
The aim of our study was to assess the visibility of the mucosa of the esophagus, stomach and duodenum after administration of water solution, $\mathrm{N}$-acetylcysteine and simethicone in comparison with the arms that were administered pure water without administration of the solution. Other parameters monitored were examination time and semiquantitative evaluation of residual fluid representing a potential risk of aspiration. A score that we defined was created to evaluate the visibility of the mucosa.

\section{MATERIALS AND METHODS}

\section{Study Protocol}

The study was performed from November 2016 to March 2017, at the Digestive Diseases Center, Vítkovice Hospital, Ostrava, Czech Republic. The endoscopists who participated in the study were experienced endoscopists who perform over 100 gastroscopies a year. The study protocol was approved by the local ethics committee and registered in the Clinical Studies Registry at ClinicalTrials.gov (NCT02967094). All patients enrolled in the study signed informed consent. Patients meeting the inclusion criteria, including age over 18 years, signed informed consent, and diagnostic upper endoscopy with the possibility of moderate sedation, with the exception of buscolysin, were included in the study. Therapeutic endoscopy, known organic gastric disease, history of upper gastrointestinal surgery, endoscopy indicated for acute gastrointestinal bleeding, dysphagia or passage disorders were considered to be exclusion criteria. Patients fasted for $6 \mathrm{~h}$ before gastroscopy.

\section{Randomization}

Patients meeting the inclusion criteria were randomized to three arms A, B, C. Upon arrival at the endoscopic workplace reception, each patient was enrolled in the table according to the order under number which was assigned an arm letter according to a random sequence. Group A was given a solution ( $100 \mathrm{~mL}$ of water $+400 \mathrm{mg}$ of $\mathrm{N}$-acetylcysteine $+20 \mathrm{mg}$ of simethicone), and group $\mathrm{C}$ was given $100 \mathrm{~mL}$ of pure water. Group B was without premedication.

\section{Procedure}

$30 \mathrm{~min}$ before gastroscopy, patients in arm A were given mucolytic solution, water in patients in arm $\mathrm{C}$, and patients in arm B were without premedication. The pa-

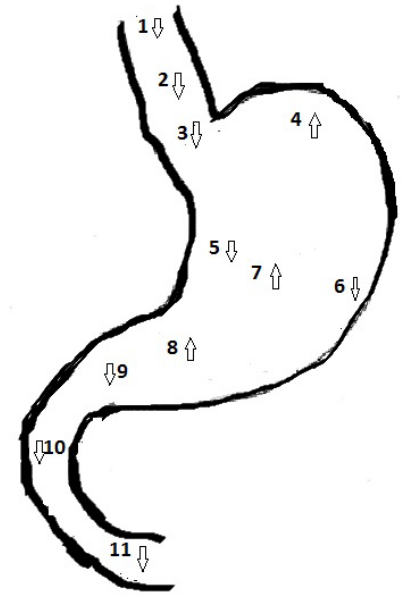

Fig. 1. Photodocumentation during upper endoskopy.

tient was then ushered to the gastroscopic room by an endoscopic nurse assisting with gastroscopy. They were then asked by the gastrologist if they were hungry, had allergies, what their symptoms were, and whether they were possibly taking antithrombotic treatment. Afterwards they were placed on the left side and a standard mouthpiece was placed between their teeth. In patients requiring moderate sedation, midazolam (1-3 mg) was intravenously administered prior to the procedure. Olympus gastroscopes (CF-HQ190L and 180L Olympus) were used for the procedure, and air insufflation was used. After that, the endoscopic procedure itself started. Before rinsing the mucosa and taking biopsies, the gastroscopist first assessed the visibility of the mucosa in the upper GIT in a total of five localities (esophagus, fundus, body and antrum of the stomach, duodenum) and determined the mucosal visibility score using our table (Table 1). At the same time he took photo documentation, a total of 11 standardized photos according to ESGE recommendations (Fig. 1) and evaluated the amount of residual fluid in the stomach. He then performed diagnostic gastroscopy, including mucosal rinsing and biopsy collection as usual, and finally recorded the total duration of gastroscopy. The patients were not further observed after the examination with the exception of the patients who were sedated, they were observed for $30 \mathrm{~min}$ in the dormitory at our endoscopic workplace. The patient, the endoscopic nurse at the operation and the performing endoscopist

Table 1. Visibility score defined as a sum of 5 scores (0-5) assessed by blinded endoscopists in the oesophagus, fornix, corpus antrum of stomach and duodenum.

\begin{tabular}{ll}
\hline 5 & Clear mucosa without fluid and coating \\
4 & Small amount of residual clear fluid \\
3 & Reduced visibility $<25 \%$ of the examine surface (bubbles, bile, food residues) \\
2 & Reduced visibility $25-50 \%$ of the examine surface \\
1 & Reduced visibility $>50 \%$ of the examine surface \\
0 & Reduced visibility $>75 \%$ of the examine surface \\
\hline
\end{tabular}


Table 2. Baseline patients characteristics $(n=134)$.

\begin{tabular}{lcccc}
\hline Arm & $\mathrm{A}(\mathrm{n}=44)$ & $\mathrm{B}(\mathrm{n}=46)$ & $\mathrm{C}(\mathrm{n}=44)$ & $P$ \\
\hline Age, mean $\pm \mathrm{SD}$, years & $52.8 \pm 15.2$ & $56 \pm 15.6$ & $52.4 \pm 18.2$ & $0.5349^{\mathrm{a}}$ \\
Sex, n (\%) & & & & \\
- male & $20(45.5)$ & $20(43,5)$ & $17(38.6)$ & $0.8010^{\mathrm{c}}$ \\
- female & $24(54.5)$ & $26(56.5)$ & $27(61.4)$ & $0.8163^{\mathrm{b}}$ \\
Indication, n (\%) & & & \\
- dyspepsia & $21(47.7)$ & $18(39.1)$ & $19(43.2)$ & $0.7127^{\mathrm{c}}$ \\
- gastroesophageal reflux disease & $15(34.1)$ & $15(32.6)$ & $11(25.0)$ & $0.6096^{\mathrm{c}}$ \\
- anemia & $1(2.3)$ & $2(4.3)$ & $2(4.5)$ & $0.8226^{\mathrm{c}}$ \\
- liver cirrhosis & $3(6.8)$ & $3(6.5)$ & $2(4.5)$ & $0.8867^{\mathrm{c}}$ \\
- before bariatric surgery & $3(6.8)$ & $3(6.5)$ & $5(11.4)$ & $0.6480^{\mathrm{c}}$ \\
- other & $1(2.3)$ & $5(10.9)$ & $5(11.4)$ & $0.2153^{\mathrm{c}}$ \\
\hline
\end{tabular}

${ }^{\mathrm{a}}$ one-way-ANOVA, ${ }^{\mathrm{b}} \log$ linear model, ${ }^{\mathrm{c}} \mathrm{X}^{2}$-test

Table 3. Visibility score assessed by the examiner blinded endoscopist.

\begin{tabular}{lcccc}
\hline Arm & $\mathrm{A}(\mathrm{n}=44)$ & $\mathrm{B}(\mathrm{n}=46)$ & $\mathrm{C}(\mathrm{n}=44)$ & $P^{a}$ \\
\hline Esophagus, mean $\pm \mathrm{SD}$ & $3.86 \pm 0.554$ & $3.74 \pm 0.612$ & $3.86 \pm 0.51$ & 0.7921 \\
Fundus, mean $\pm \mathrm{SD}$ & $3.02 \pm 0.821$ & $3 \pm 0.76$ & $3.25 \pm 0.615$ & 0.2137 \\
Corpus, mean $\pm \mathrm{SD}$ & $2.95 \pm 0.746$ & $2.78 \pm 0.892$ & $3.00 \pm 0.682$ & 0.3789 \\
Antrum, mean $\pm \mathrm{SD}$ & $3.68 \pm 0.518$ & $3.65 \pm 0.566$ & $3.61 \pm 0.655$ & 0.9633 \\
Duodenum, mean $\pm \mathrm{SD}$ & $3.89 \pm 0.387$ & $3.83 \pm 0.608$ & $3.86 \pm 0.51$ & 0.9690 \\
SUM, mean $\pm \mathrm{SD}$ & $17.4 \pm 1.9$ & $17 \pm 2.01$ & $17.6 \pm 1.81$ & 0.3242 \\
Residual fluid, mean $\pm \mathrm{SD}$ & $2.48 \pm 0.698$ & $2.36 \pm 0.712$ & $2.18 \pm 0.62$ & 0.1182 \\
Duration, mean $\pm \mathrm{SD}$, min & $7.84 \pm 1.46$ & $7.87 \pm 1.64$ & $7.55 \pm 1.74$ & 0.3108 \\
\hline
\end{tabular}

${ }^{a}$ One-way-ANOVA

were blinded. In the second period, two other blinded endoscopists determined the scores of visibility from the acquired photo documentation.

\section{Endpoints}

The primary endpoint was the mucosal visibility score assessed by the examiner blinded by the gastroscopist. It given by the sum of 5 scores $0-5$ (esophagus, fundus, body, gastric antrum, duodenum), a total of 0-25. The secondary endpoint was the visibility score evaluated according to 11 static photographs by two blinded endoscopists, again the sum of 5 scores 0-5 (esophagus, fundus, body, gastric antrum, duodenum).

Other parameters monitored were the amount of residual fluid in the stomach assessed by the performing gastroscopeist (0 - no fluid, 1 - a small amount that cannot be aspirated, 2 - a small amount that can already be aspirated, 3 - gastric juice) and gastroscopy time measured from insertion to removal of the endoscope.

Prior to the start of the study, standard diagnostic gastroscopy was performed in 100 patients; consequently, a visibility score, whose overall average was 16.36 , was determined. Based on power analysis, a minimum sample size of 33 patients per arm was calculated using $\alpha=0.05$ and $\beta=0.1977$, assuming a $10 \%$ increase in visibility score was considered clinically significant. The correlation be- tween the quantitative variables was tested using One-way Anova, the correlation between the qualitative variables was determined using the Chi-squared test and the loglinear model. Visibility scores, residual fluid levels, and gastroscopy time assessed by the performing gastroscopeist were analyzed between arms using One-way Anova. Wilcoxon's robust paired test was used to compare clarity scores between two blinded endoscopists. The $P$-value $<0.0001$ was considered statistically significant.

\section{RESULTS}

\section{Patients}

A total of 134 patients who underwent diagnostic gastroscopy were included and randomized into three arms (Fig. 2). The baseline characteristics, including age, sex, and indication for examination, were comparable between the arms (Table 2). The primary endpoint, i.e. the total visibility score evaluated by the performing gastroscopist, did not show a statistically significant difference between the individual arms $17.4 \pm 1.9$ (A) vs. $17.0 \pm 2.0$ (B) vs. $17.6 \pm 1.8(\mathrm{C})(P=0.32)$. Examination time was also comparable $(7.8 \pm 1.5$ vs. $7.9 \pm 1.6$ vs. $7.6 \pm 1.7 \mathrm{~min}, P=0.31)$, as was the amount of residual fluid in the stomach $(2.5 \pm$ 0.7 vs. $2.4 \pm 0.7$ vs. $2.2 \pm 0.6, P=0.12$ ) (Table 3 ). The sec- 


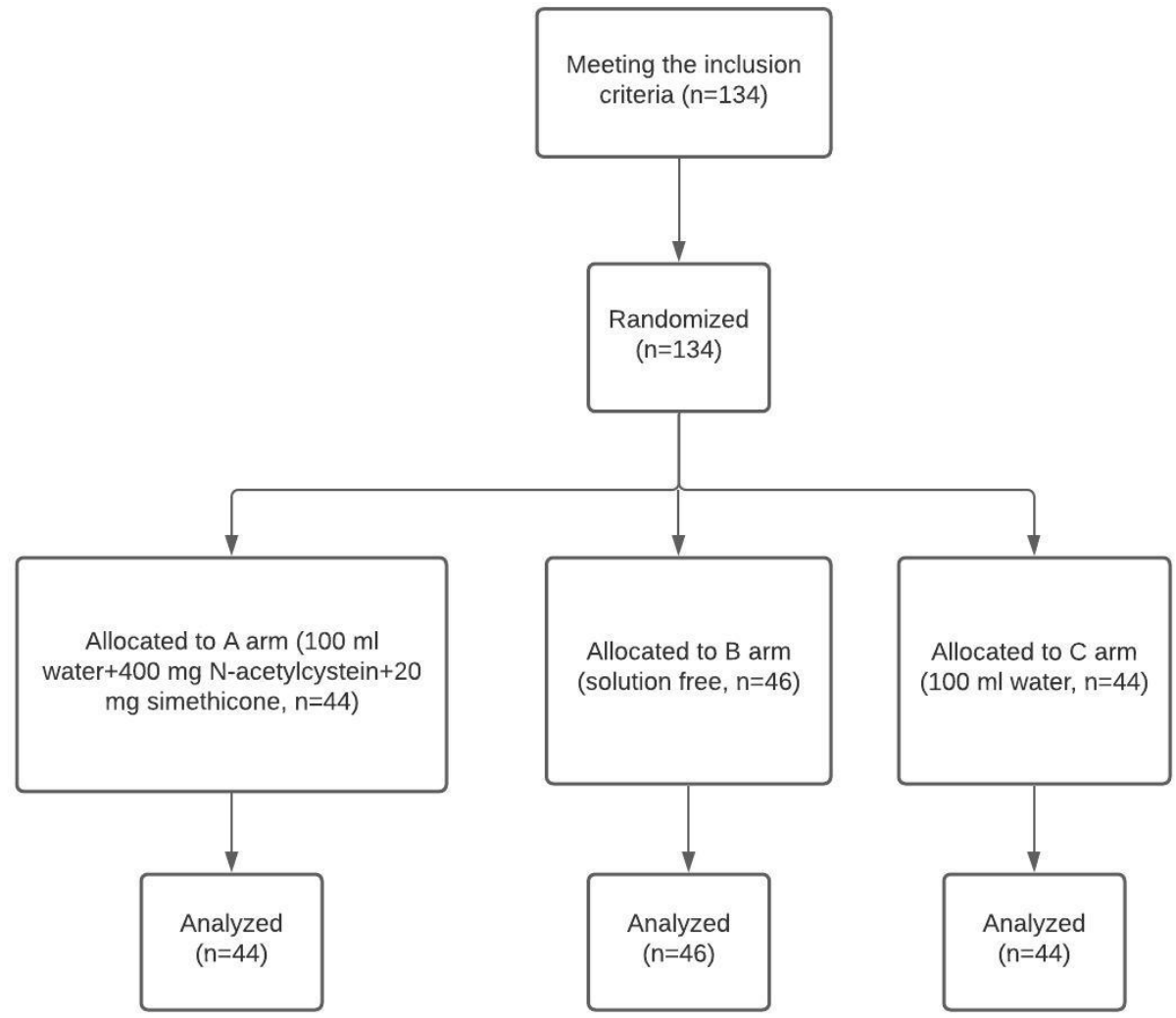

Fig. 2. Study flow diagram.

Table 4. Visibility score assessed by two others $(1,2)$ endoscopists.

\begin{tabular}{|c|c|c|c|c|c|c|c|c|c|c|c|c|}
\hline \multirow{2}{*}{$\begin{array}{l}\text { Arm } \\
\text { Endoscopists, } \Delta, \mathrm{P}\end{array}$} & \multicolumn{4}{|c|}{$A(n=44)$} & \multicolumn{4}{|c|}{$B(n=46)$} & \multicolumn{4}{|c|}{$C(n=44)$} \\
\hline & 1 & 2 & $\Delta$ & $P^{a}$ & 1 & 2 & $\Delta$ & $P^{a}$ & 1 & 2 & $\Delta$ & $P^{a}$ \\
\hline \multirow[t]{2}{*}{ Esophagus, mean \pm SD } & 4.16 & 2.93 & -1.23 & $<0.0001$ & 3.72 & 2.7 & -1.02 & $<0.0001$ & 4.16 & 2.66 & -1.5 & $<0.0001$ \\
\hline & \pm 1.03 & \pm 0.625 & \pm 0.886 & & \pm 1.24 & \pm 0.84 & \pm 0.931 & & \pm 1.06 & \pm 0.608 & \pm 0.928 & \\
\hline \multirow[t]{2}{*}{ Fundus, mean $\pm \mathrm{SD}$} & 3.43 & 2.2 & -1.23 & $<0.0001$ & 3.5 & 2.2 & -1.3 & $<0.0001$ & 3.89 & 2.34 & -1.55 & $<0.0001$ \\
\hline & \pm 1.26 & \pm 0.878 & \pm 1.03 & & \pm 1.09 & \pm 0.91 & \pm 0.813 & & \pm 1.15 & \pm 0.987 & \pm 0.901 & \\
\hline \multirow[t]{2}{*}{ Corpus, mean \pm SD } & 2.91 & 2.2 & -0.705 & $<0.0001$ & 2.83 & 1.98 & -0.848 & $<0.0001$ & 3.48 & 2.23 & -1.25 & $<0.0001$ \\
\hline & \pm 0.83 & \pm 0.93 & \pm 0.904 & & \pm 1.23 & \pm 1.14 & \pm 0.918 & & \pm 1.17 & \pm 1.03 & \pm 0.967 & \\
\hline \multirow[t]{2}{*}{ Antrum, mean $\pm \mathrm{SD}$} & 4.52 & 3.32 & -1.20 & $<0.0001$ & 4.22 & 2.96 & -1.26 & $<0.0001$ & 4.48 & 3.16 & -1.32 & $<0.0001$ \\
\hline & \pm 0.849 & \pm 0.934 & \pm 1.00 & & \pm 1.01 & \pm 1.03 & \pm 1.02 & & \pm 0.876 & \pm 1.03 & \pm 0.771 & \\
\hline \multirow[t]{2}{*}{ Duodenum, mean $\pm \mathrm{SD}$} & 4.25 & 3.07 & -1.18 & $<0.0001$ & 3.91 & 2.57 & -1.35 & $<0.0001$ & 3.95 & 2.61 & -1.34 & $<0.0001$ \\
\hline & \pm 0.991 & \pm 0.759 & \pm 0.724 & & \pm 1.35 & \pm 0.86 & \pm 0.924 & & \pm 1.31 & \pm 0.868 & \pm 1.2 & \\
\hline \multirow[t]{2}{*}{$\mathrm{SUM}$, mean $\pm \mathrm{SD}$} & 19.3 & 13.7 & -5.55 & $<0.0001$ & 18.2 & 12.4 & -5.78 & $<0.0001$ & 20 & 13 & -6.95 & $<0.0001$ \\
\hline & \pm 2.9 & \pm 2.54 & \pm 2.31 & & \pm 3.39 & \pm 3.32 & \pm 2.3 & & \pm 2.83 & \pm 3.18 & \pm 2.31 & \\
\hline
\end{tabular}

${ }^{a}$ Wilcoxon's robust paired test

ondary endpoint, the visibility score evaluated by blinded endoscopists from the acquired photo documentation, was different for both endoscopists. However, no statistical difference was found between the individual arms in their evaluation, thus confirming the results evaluated directly by the performing gastroscopist (Table 4).

\section{DISCUSSION}

The quality of upper endoscopy has been one of the most discussed topics in digestive endoscopy in recent years. Above all, a sufficiently clear mucosa is very im- portant for the diagnosis of lesions in the upper digestive tract. Simethicone and N-acetylcysteine are substances that are used, especially in Asian countries, to improve the visibility of the mucosa at the upper endoscopy.

However, the optimal dose, amount and timing of administration prior to gastroscopy are still unclear. In our study, we used a formula that is used in Japan and was used in a Japanese study that diagnosed early gastric cancer ${ }^{13}$. One of the reasons why our study failed to demonstrate the positive effect of the mucolytic solution we used to increase the clarity of the mucosa in the upper gastrointestinal tract may be low doses of the individual components of the solution. Published studies 
have shown mainly the effect of simethicone in higher doses, administered either alone or in combination with $\mathrm{N}$-acetylcysteine. Keeratichananont et al used simethicone at a dose of $133.3 \mathrm{mg}$ in combination with water and demonstrated its effect in increasing the visibility of the mucosa in the esophagus, stomach and duodenum ${ }^{8}$. Bertoni et al. also showed the effect of simethicone alone even at a dose of $65 \mathrm{mg}$ in combination with water ${ }^{11}$. A Portuguese study by Elvas et al. then demonstrated the efficacy of $100 \mathrm{mg}$ simethicone with water, but also its combination with $600 \mathrm{mg} \mathrm{N}$ - acetylcysteine, mainly to increase the visibility of the mucosa in the esophagus and stomach ${ }^{10}$. In contrast, Monrroy et al. did not confirm the efficacy of simethicone alone at $200 \mathrm{mg}$, however, its combination with $\mathrm{N}$-acetylcysteine at 500 and $1000 \mathrm{mg}$ increased the overall clarity of the upper gastrointestinal mucosa ${ }^{4}$. Other parameters discussed that could affect the overall visibility score are the total amount of solution administered and the time of its administration before gastroscopy. In our study, we believe that the total amount of water in the administered solution, i.e. $100 \mathrm{~mL}$, did not have a direct effect on the resulting visibility score, as the overall visibility score was similar between the observed arms. This is also evidenced by available studies that have shown the effect of simethicone or, alternatively, $\mathrm{N}$-acetylcysteine, where the amount of water in the administered solution ranged from 60 to $100 \mathrm{~mL}$ (ref., ${ }^{4,5,7-10}$ ). Also, the time of administration of the solution, i.e. 30 min before gastroscopy, should not have any significant effect on the result of the overall visibility score in our study. Based on the available data, the administration time of the solution, that is $15-30 \mathrm{~min}$ before gastroscopy, appears to be effective $^{4,5,7-10}$.

\section{CONCLUSION}

Our study did not show a higher score of mucosal visibility in the upper gastrointestinal tract after administration of a solution containing $\mathrm{N}$-acetylcysteine and simethicone. Further research on this issue is needed in the future. We believe that it can be based on the same concept, however, the dose of simethicone and possibly $\mathrm{N}$-acetylcysteine must be increased on the basis of available data.

\section{ABBREVIATIONS}

ESGE, European Society of Gastrointestinal endoscopy; USA, United States of America.

Author contributions: MS: manuscript writing, literature search; PF: study registration at ClinicalTrials.gov, final approval; MS, BP, PF, MH: examiner blinded endoscopist; BP: application to the local ethics committee; $\mathrm{MH}$ : data collection; $\mathrm{MH}, \mathrm{PF}$, OU: design of the study; $\mathrm{MH}$ : statistical analysis; PF, OU: blinded endoscopist determined the scores of visibility from the acquired photo documentation. All authors read and approved the final manuscript.

Conflict of interest statement: None declared.

\section{REFERENCES}

1. Peery AF, Dellon ES, Lund J, Crockett SD, McGowan ChE, Bulsiewicz WJ, Gangarosa LM, Thiny MT, Stizenberg K, Morgan DR, Ringel Y, Kim HP, DiBonaventura MD, Carroll ChF, Allen JK, Cook SF, Sandler RS, Kappelman MD, Shaheen NJ. Burden of gastrointestinal disease in the United States: 2012 update. Gastroenterology 2012;143(5):117987.

2. Januszewicz W, Kaminski MF. Quality indicators in diagnostic upper gastrointestinal endoscopy. Therap Adv Gastroenterol 2020;13:1756284820916693. doi: 10.1177/1756284820916693

3. Bisschops R, Areia M, Coron E, Dobru D, Kaskas B, Kuvaev R, Pech O, Ragunath K, Weusten B, Familiari P, Domagk D, Valori R, Kaminski MF, Spada C, Bretthauer M, Bennett C, Senore C, Dinis-Ribeiro M, Rutter MD. Performance measures for upper gastrointestinal endoscopy: a European Society of Gastrointestinal Endoscopy (ESGE) Quality Improvement Initiative. Endoscopy 2016;48:843-64.

4. Monroy H, Vargas Jl, Glasinovic E, Candia R, Azua E, Galvez C, Rojas C, Cabrera N, Vidaurre J, Alvarez N, Gonzales J, Espino A, Gonzales $\mathrm{R}$, Parra-Blanco A. Use of $\mathrm{N}$-acetylcysteine plus simethicone to improve mucosal visibility during upper $\mathrm{Gl}$ endoscopy: a double-blind, randomized controlled trial. Gastrointesti Endosc 2018;87(4):986-93. doi: 10.1016/j.gie.2017.10.005

5. Chang Ch, Chen S, Lin Ch, Hsieh Ch, Lou H, Suk F, Pan S, Wu M, Chen J, ChenY.Premedication with pronase or $\mathrm{N}$-acetylcysteine improves visibility during gastroendoscopy: An endoscopist-blinded, prospective, randomized study. World J Gastroenterol 2007;13(3):444-47.

6. Hassan C, East J, Radaelli F, Spada C, Benamouzig R, Bisschops R, Bretthauer M, Dekker E, Dinis-Ribeiro M, Ferlitsch M, Fuccio L, Awadie H, Gralnek I, Jover R, Kaminski MF, Pellise M, Triantafyllou K, Vanella G, Mangas-Sanjuan C, Frazzoni L, Van Hooft JE, Dumonceau JM. Bowel preparation for colonoscopy: European Society of Gastrointestinal Endoscopy (ESGE) Guideline-Update 2019. Endoscopy 2019;51(8):775-94.

7. Chang W, Yeh M, Hsu H, Chen H, Hu M. Efficacy of simethicone and $\mathrm{N}$-acetylcysteine as premedication in improving visibility during upper endoscopy. J Gastroenterol Hepatol 2014;29(4):769-74.

8. Keeratichananont S, Sobhonslidsuk A, Kitiyakara T, Achalanan N, Soonthornpun $\mathrm{S}$. The role of liquid simethicone in enhancing endoscopic visibility prior to Esophagogastroduodenoscopy (EGD): A prospective, randomized, double-blinded, placebo-controlled trial: J Med Assoc Thai 2010;93(8): 892-7.

9. Veeraraghavan K, Abel J, Shreyas V, Malini T, Vijayaraghavan D, Sangeetha A, Kurien G. Efficacy of simethicone and N-acetylcystein combination premedication prior to esophagogastroduodenoscopy to improve mucosal visibility-a prospective double blinded randomized placebo controlled trial. Endoscopy 2018;50(04):75.

10. Elvas L, Areia M, Brito D, Alves S, Saraiva S, Cadime AT. Premedication with simethicone and $\mathrm{N}$-acetylcysteine in improving visibility during upper endoscopy: a double-blind randomized trial. Endoscopy 2017;49(2):139-45.

11. Bertoni G, Gumina C, Conigliaro R, Ricci E, Staffetti J, Mortilla MG, Pacchione D. Randomized placebo-controlled trial of oral liquid simethicone prior to upper gastrointestinal endoscopy. Endoscopy 1992;24(4):268-70.

12. Lai EJ, Calderwood AH, Doros G, Fix OK, Jacobson BC. The Boston Bowel Preparation Scale: A valid and reliable instrument for colonoscopy-oriented research. Gastrointest Endosc 2009;69(3):620-25.

13. Yao K. The endoscopic diagnosis of early gastric cancer. Ann Gastroenterol 2013;26(1):11-22. 